\title{
Article \\ Surface Hydrophobic Modification of Biochar by Silane Coupling Agent KH-570
}

\author{
Muxi Zhang ${ }^{1,2}$, Hongxiang Zhu ${ }^{3}$, Beidou $\mathrm{Xi}^{1,2,4}$, Yuxin Tian ${ }^{1,2}$, Xiaojie Sun ${ }^{1,2, *}$, Hongxia Zhang ${ }^{1,2, *}$ \\ and Beibei $\mathrm{Wu}^{1,2}$
}

Citation: Zhang, M.; Zhu, H.; Xi, B.; Tian, Y.; Sun, X.; Zhang, H.; Wu, B. Surface Hydrophobic Modification of Biochar by Silane Coupling Agent KH-570. Processes 2022, 10, 301. https://doi.org/10.3390/pr10020301 Academic Editor: Carmen Branca

Received: 27 December 2021

Accepted: 31 January 2022

Published: 2 February 2022

Publisher's Note: MDPI stays neutral with regard to jurisdictional claims in published maps and institutional affiliations.

Copyright: (c) 2022 by the authors. Licensee MDPI, Basel, Switzerland. This article is an open access article distributed under the terms and conditions of the Creative Commons Attribution (CC BY) license (https:// creativecommons.org/licenses/by/ $4.0 /)$.
1 Guangxi Key Laboratory of Environmental Pollution Control Theory and Technology, Guilin University of Technology, Guilin 541004, China; zhangmuxi2022@163.com (M.Z.); xibeidou@263.net (B.X.); ttianyyxx@163.com (Y.T.); beibei_wu@webmail.hzau.edu.cn (B.W.)

2 Guangxi Collaborative Innovation Center for Water Pollution Control and Water Safety in Karst Area, Guilin University of Technology, Guilin 541004, China

3 College of Light Industry and Food Engineering, Guangxi University, Nanning 530004, China; zhx@gxu.edu.cn

4 State Environmental Protection Key Laboratory of Simulation and Control of Groundwater Pollution, Chinese Research Academy of Environmental Sciences, Beijing 100012, China

* Correspondence: sunxiaojie@glut.edu.cn (X.S.); zhx75@glut.edu.cn (H.Z.); Tel.: +86-15078329789 (X.S.)

\begin{abstract}
Biochar-amended soil cover (BSC) in landfills can improve the oxidation of methane. However, adding biochar can cause a larger amount of rainwater to enter the soil cover and landfill because it increases the permeability of the soil cover, which increases leachate production. Improving the hydrophobicity and waterproof ability of BSC is expected to reduce rainwater that goes into landfills. Silane coupling agent KH-570 is used to modify biochar to improve its hydrophobicity and waterproof ability after being added to the soil cover. The waterproofness of hydrophobic biocharamended soil cover (HBSC) was studied by conducting a precipitation simulation test. Results showed that the optimum hydrophobicity of the surface-modified biochar was obtained when the mass fraction of $\mathrm{KH}-570$ was $7 \%$, the biochar dosage was $7 \mathrm{~g}$, and the modification temperature was $60{ }^{\circ} \mathrm{C}$. In these conditions, the contact angle was $143.99^{\circ}$ and the moisture absorption rate was $0.10 \%$. The analysis results of thermogravimetric, X-ray diffractometer and scanning electron microscopy before and after the biochar modification showed that $\mathrm{KH}-570$ formed a hydrophobic organic coating layer on the biochar surface, indicating that the surface hydrophobic modification of biochar was successfully carried out by silane coupling agent. The waterproof ability of HBSC was significantly better than that of BSC in the simulated precipitation test.
\end{abstract}

Keywords: silane coupling agents; biochar; hydrophobic modification; landfill cover

\section{Introduction}

Landfill soil cover has been used to oxidize methane to reduce methane emission [1,2]. The $\mathrm{CH}_{4}$ emission reduction of landfill depends on the choice of soil cover material. In contrast to traditional soil cover, the biocover in landfill have been extensively studied to increase the aerobic oxidation of methane [3]. Many kinds of biocover materials include compost [4-6], mineralized refuse [7], and solidified sludge [8]. However, $\mathrm{CH}_{4}$ oxidation capacity of traditional landfill soil cover material was generally insufficient $[9,10]$. Biomassbased carbon materials have attracted attention due to their economical, sustainable, and environmentally friendly features [11]. Biochar can be considered as a suitable and alternate material as a final cover system for landfills because its high specific surface area and high porosity can improve the permeability of the biocover and promote the growth and reproduction of methanotrophs [1,12-14]. Prior studies noted that average $\mathrm{CH}_{4}$ removal efficiencies were up to $85.2 \%$ for biochar-amended soil cover (BSC) [6].

However, a number of hydrophilic groups, such as carboxyl and hydroxyl groups, are on the surface of biochar $(C>60 \%)$ [15]. As the content of biochar added to the soil 
cover increases, so does the permeability coefficient of the cover. Studies have shown that the permeability coefficient of the soil with $10 \%$ biochar added has been more than $10^{-7} \mathrm{~cm} / \mathrm{s}$ [16]. The increase of permeability coefficient leads to the increase of rainwater into the methane oxide layer and landfill. Water content has been found to be an important environmental factor that controls methane oxidation and adsorption capacity of landfill cover soil $[17,18]$. The increase of rainwater entering the methane oxide layer decreases methane oxidation and adsorption efficiency [19]. In addition, the increase of rainwater entering the landfill leads to the increase of leachate production, thereby increasing the cost of leachate treatment. Therefore, a problem to be solved is how to reduce rainwater entering the soil cover after adding biochar.

$\mathrm{KH}-570$ is an environmentally friendly hydrophobic modifier that has been studied and applied in environmental pollution control [20]. For example, Chen [21] used four kinds of silane coupling agents to modify the interfaces of composites and found that KH-570 modified composite possessed the best mechanical properties and water resistance. Therefore, in this study, silane coupling agent $\mathrm{KH}-570$ was selected as the modifier to conduct an experiment on hydrophobic modification of biochar, thereby improving its hydrophobicity and reducing rainwater that enters the soil cover and landfill. The hydrophobic properties of biochar were tested under various concentrations of modifier, dosages, and modification temperatures to determine the optimal hydrophobic modification conditions. A simulated landfill cover precipitation experiment was conducted to study the waterproof ability of modified biochar. The hydrophobic modification of biochar was conducted to develop materials to improve the hydrophobic permeability of the landfill cover layer, providing technical support for methane emission reduction in landfills.

\section{Experimental}

\subsection{Materials}

Biochar was purchased from Desheng Carbon Industry Co. Ltd., silane coupling agent KH-570 from Sinopharm Chemical Reagent Co. Ltd., ethanol absolute (analytically pure) from Cologne Chemicals Co. Ltd., and acetic acid (analytically pure) from Sinopharm Chemical Reagent Co. Ltd. (all manufacturers are based in China).

\subsection{Preparation of Biochar}

The biochar used was produced by pyrolysis of discarded rice straw in a completely anoxic environment through pyrolysis at $500{ }^{\circ} \mathrm{C}$ [15]. Total pore volume of adsorption was $0.07 \mathrm{~cm}^{3} / \mathrm{g}$. The biochar used in the test was alkaline, with high $\mathrm{C}$ content $(64.2 \%)$ and low $\mathrm{P}(0.16 \%)$ and $\mathrm{K}(0.33 \%)$ contents. The main component of rice straw was cellulose, and its main structures were sieve tube and conduit, which mainly account for the large specific surface area of rice straw biochar [15].

\subsection{Surface Modification of Biochar with $\mathrm{KH}-570$}

First, biochar was added to alcohol-water solution to hydrolyze it sufficiently. The volume proportion of ethanol absolute and water was $1: 1$, and $0.1 \mathrm{~mol} / \mathrm{L}$ acetic acid was used to adjust $\mathrm{pH}$ to 4 . Then, the mixture was stirred in a water bath at $30{ }^{\circ} \mathrm{C}-70{ }^{\circ} \mathrm{C}$ for $30 \mathrm{~min}$. Second, the prepared silane coupling agent $\mathrm{KH}-570$ was added into the above solution and stirred for $2 \mathrm{~h}$. Third, the reaction products were filtered and washed with ethanol absolute several times. Finally, the surface hydrophobic modified biochar was obtained by drying in an electric blast drying oven at $50{ }^{\circ} \mathrm{C}$ for $6 \mathrm{~h}$.

\subsection{Hydrophobic Modification Mechanism of KH-570}

Silane coupling agent $\mathrm{KH}-570$ represents a type of important difunctional group modifiers that can react with adsorbed water on organic molecules and inorganic surfaces to form a strong bond [22]. Figure 1 shows the surface hydrophobic modification reaction mechanism of KH-570. This silane coupling agent undergoes hydrolysis, dehydration, and condensation to form oligomers. The dehydration of oligomers and hydroxyl groups on 
the surface of the biochar formed partial covalent bonds, which coated the biochar surface with coupling agent and increased the hydrophobicity [15].

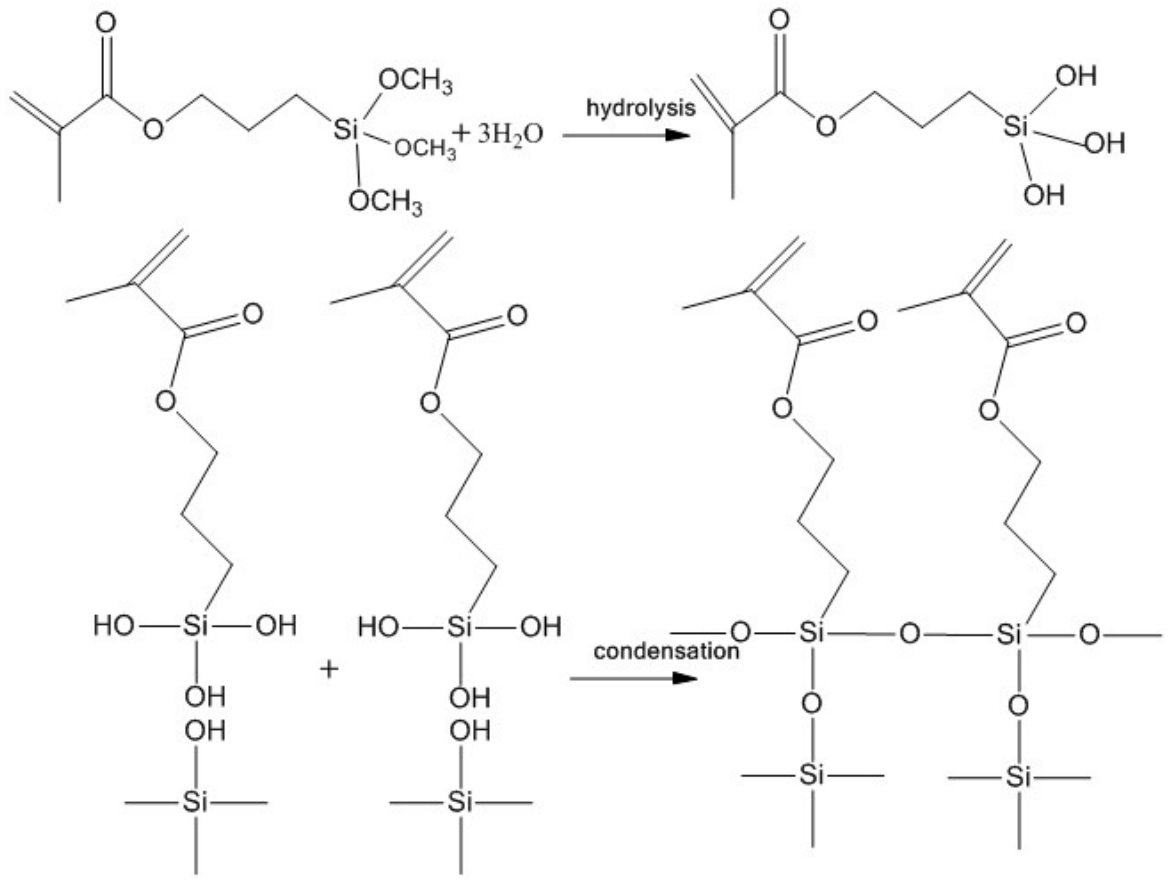

Figure 1. Hydrophobic modification mechanism of KH-570.

\subsection{Characterization Analysis}

The changes of functional groups of biochar before and after modification were characterized by Fourier transform infrared spectroscopy (FTIR) (IS10, Thermo Fisher Scientific, Madison, WI, USA). The morphology and structure of biochar before and after modification were characterized by scanning electron microscopy (SEM) (JSM-7900F Plus, Nidec Corporation, Kyoto, Japan). The thermogravimetric (TGA) curves of biochar before and after modification were measured by synchronous thermal analyzer to characterize its thermal stability (SDT-Q600, Waters, Milford, MA, USA, USA). The phase of biochar before and after modification was analyzed by X'Pert3 Power multifunctional X-ray diffractometer (XRD) (PANalytical B.V., Alemlo, The Netherlands). Surface contact angle was an important parameter for evaluating hydrophobicity or hydrophilicity. JC2000D1 contact angle tester (Shanghai Zhongchen Digital Technology Equipment Co. Ltd., Shanghai, China) was used to determine the wettability of biochar before and after modification. The contact angle was less than or equal to $90^{\circ}$ for hydrophilicity and greater than $90^{\circ}$ for hydrophobicity [23]. Hygroscopicity refers to the ability of a solid material to absorb water from air. The lower the moisture content, the better its hydrophobicity [23,24]. Then, $4 \mathrm{~g}$ of dried to constant weight original biochar and modified biochar were evenly spread on glass sheets and placed at room temperature for $24 \mathrm{~h}$. Their mass changes were measured and their moisture absorption rates were calculated. The moisture absorption rates can be calculated as follows:

$$
\text { moisture absorption rates }=\left[\left(\mathrm{m}_{2}-\mathrm{m}_{1}\right) / \mathrm{m}_{1}\right] \times 100 \%
$$

where $\mathrm{m}_{1}$ is the drying mass, $\mathrm{g}$; and $\mathrm{m}_{2}$ is the mass after $24 \mathrm{~h}$ of hygroscopicity, $\mathrm{g}$.

\subsection{Waterproofing Experiment}

In this study, a simple model was designed to simulate the actual landfill soil cover (Figure 2) to compare the waterproof performance of biochar before and after modification. Biochar-amended soil and hydrophobic biochar-amended soil, in which the volume proportion of biochar or modified biochar and soil was 1:5 [16], were, respectively, added into the 
model. The material was repeatedly compacted, with one side flush with the water guide plate. The slope of the top was adjusted to $7 \%$ according to the Technical Specification for Sealing of Sanitary Landfill Sites of Domestic Waste (China, 2017). The initial water content of the cover material was adjusted to approximately $22 \%$. Then, $2.5 \mathrm{~L}$ water was evenly sprayed by simulated precipitation at the top of the compacted slope, and the water flowed out of the water guide plate into the collection container. The volume of outflow water was measured.
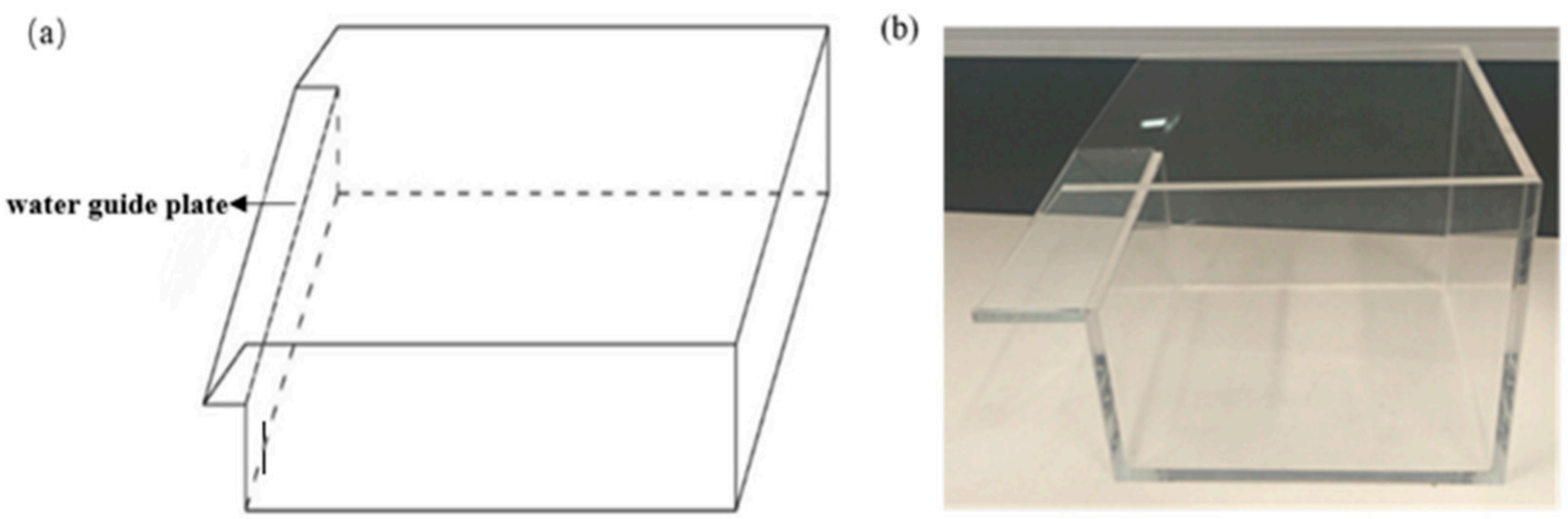

Figure 2. Schematic and physical map of a simple landfill soil cover model.

\section{Results and Discussion}

\subsection{Effect of Mass Fraction of KH-570 on Surface Hydrophobic Properties of Modified Biochar}

Under the biochar dosage of $5 \mathrm{~g}$ and modification temperature of $70{ }^{\circ} \mathrm{C}$, the effects of various mass fractions of $\mathrm{KH}-570$ on the surface hydrophobicity of biochar were investigated. As shown in Figure 3, the contact angle of biochar was $7.04^{\circ}$ and the water absorption rate was $0.22 \%$ without the addition of $\mathrm{KH}-570$. With the increase of the mass fraction of $\mathrm{KH}-570$, the contact angle of the modified biochar increased initially, and then showed a trend of fluctuation and decline. The reason was that when the mass fraction of $\mathrm{KH}-570$ continued increasing $(<7 \%)$, the hydrophobic performance improved as more hydrophilic groups on the biochar surface were replaced by hydrophobic groups. However, when the mass fraction of KH-570 exceeded 7\%, the siloxane anion generated by the hydrolysis of $\mathrm{KH}-570$ formed a bridge, leading to the flocculation of the powder, thereby affecting the hydrophobic modification effect of the biochar [25]. The contact angle of modified biochar reached $131.99^{\circ}$ and the water absorption rate was $0.04 \%$ when the mass fraction of $\mathrm{KH}-570$ was $7 \%$. Therefore, the optimal mass fraction of $\mathrm{KH}-570$ was $7 \%$ when the biochar dosage was $5 \mathrm{~g}$ and the modification temperature was $70{ }^{\circ} \mathrm{C}$.

\subsection{Effect of Biochar Addition on Surface Hydrophobic Properties}

The effect of the additional amount of biochar on the surface hydrophobic performance was studied at $70{ }^{\circ} \mathrm{C}$ modification temperature and $7 \%$ mass fraction of $\mathrm{KH}-570$. As shown in Figure 4, the contact angle reached a maximum value of $141.99^{\circ}$, and the moisture absorption rate correspondingly had a minimum value of $0.08 \%$ when the biochar dosage was $7 \mathrm{~g}$, indicating that the hydrophilic groups on the surface of biochar were basically replaced by the hydrophobic groups of $\mathrm{KH}-570$, forming a hydrophobic organic cover on the surface of biochar in the form of chemical bonding, which resulted in the transformation of biochar from hydrophilic surface to hydrophobic surface [25]. However, when the biochar dosage increased from $7 \mathrm{~g}$ to $13 \mathrm{~g}$, the contact angle decreased from $141.99^{\circ}$ to $125.49^{\circ}$, and the moisture absorption rate increased from $0.08 \%$ to $0.10 \%$, indicating that the hydrophilic group on the surface of biochar could not be completely replaced, and the hydrophobic effect worsened. Therefore, the optimal dosage of biochar was $7 \mathrm{~g}$ when the mass fraction of $\mathrm{KH}-570$ was $7 \%$ and the modification temperature was $70{ }^{\circ} \mathrm{C}$. 


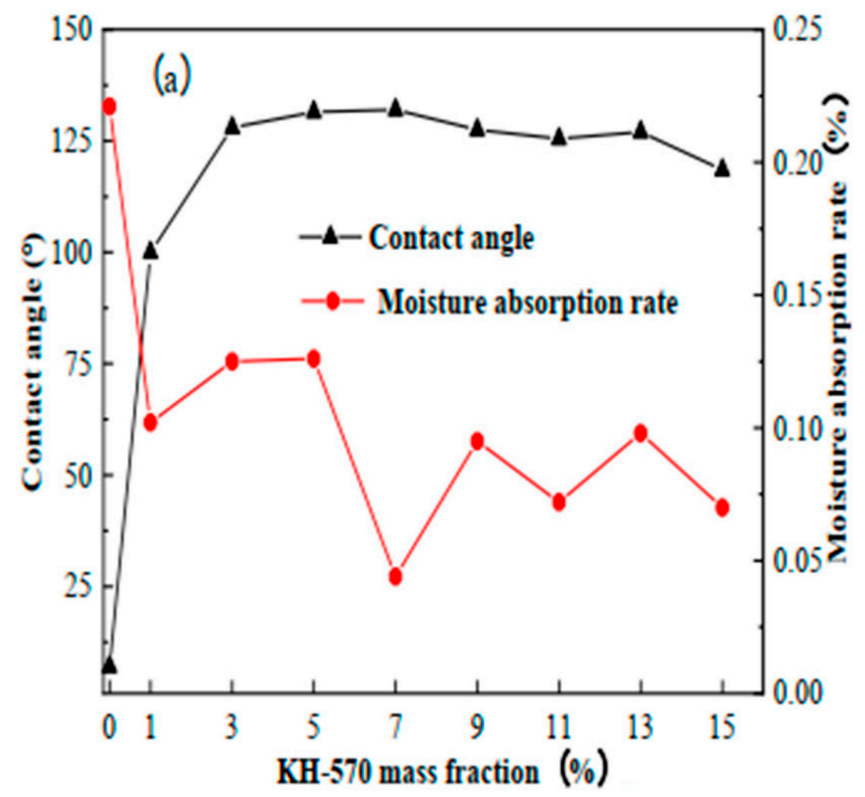

(b)

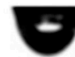

$\mathrm{CA}=131.99^{\circ}$

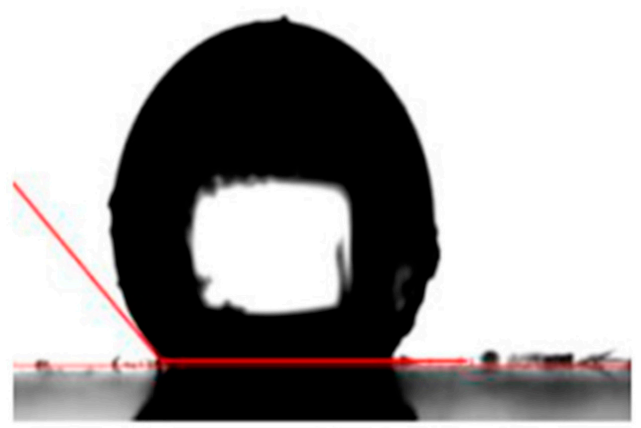

$\mathrm{KH}-570$ mass fraction $=7 \%$

Figure 3. (a) Contact angles and moisture absorption rates of biochar modified by $\mathrm{KH}-570$, and (b) contact angle of modified biochar when $\mathrm{KH}-570$ mass fraction was $7 \%$.
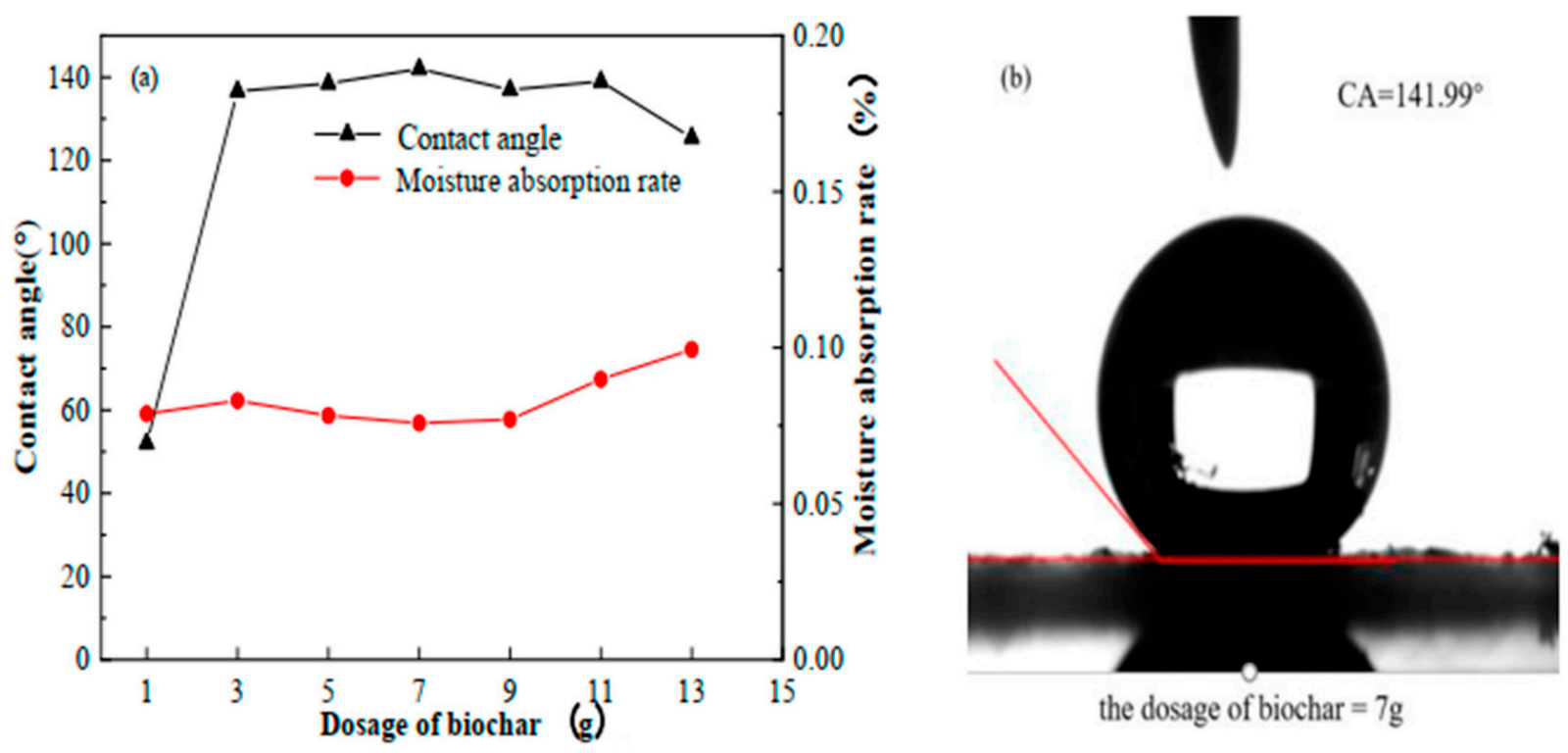

Figure 4. (a) Contact angles and moisture absorption rates of modified biochar with different dosage, and (b) contact angle of modified biochar when the dosage of biochar was $7 \mathrm{~g}$.

\subsection{Effect of Reaction Temperature on Surface Hydrophobicity of Modified Biochar}

The effect of the reaction temperature on the surface hydrophobicity of biochar was studied when the mass fraction of $\mathrm{KH}-570$ was $7 \%$ and the biochar dosage was $7 \mathrm{~g}$. The test results of the contact angle and moisture absorption rates under $30,40,50,60$, and $70{ }^{\circ} \mathrm{C}$ are shown in Figure 5. The hygroscopicity decreased greatly when the reaction temperature reached $50{ }^{\circ} \mathrm{C}$, and modified biochar changed from hydrophilic surface to hydrophobic surface. The maximum contact angle of modified biochar was $143.99^{\circ}$, and the minimum moisture absorption rate was $0.10 \%$ until the reaction temperature reached $60{ }^{\circ} \mathrm{C}$. When the reaction temperature was increased, the contact angle decreased and the moisture absorption rate increased. This result may be due to the fracture and release of a large amount of hydrophilic oxygen-containing functional groups in biomass [24]. Therefore, the 
optimal modification temperature was $60^{\circ} \mathrm{C}$ when the mass fraction of $\mathrm{KH}-570$ was $7 \%$ and the biochar dosage was $7 \mathrm{~g}$.
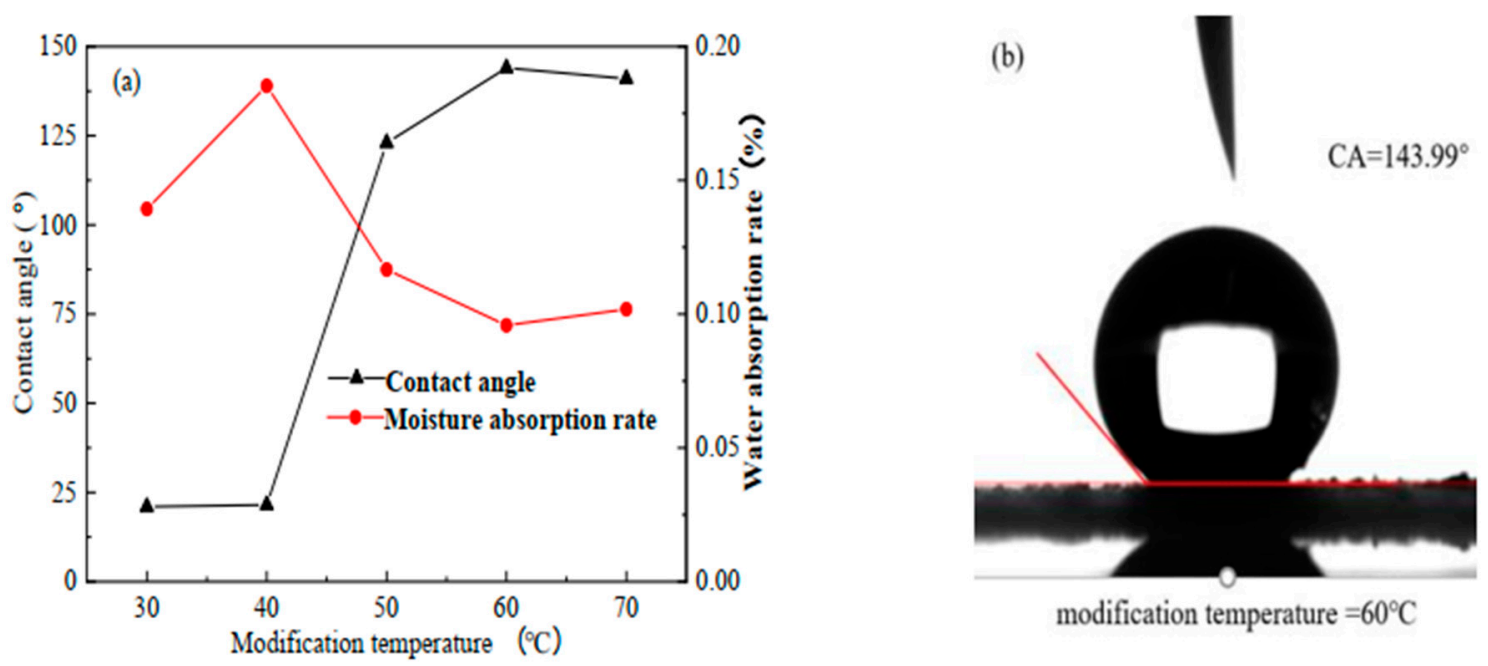

Figure 5. (a) Contact angles and moisture absorption rate of modified biochar at different reaction temperatures, and (b) contact angle of modified biochar when temperature was $60^{\circ} \mathrm{C}$.

In summary, the hydrophobic modified biochar was prepared under the following conditions: $7 \%$ mass fraction of $\mathrm{KH}-570,7 \mathrm{~g}$ biochar dosage, and $60{ }^{\circ} \mathrm{C}$ modification temperature. In these conditions, the contact angle was $143.99^{\circ}$ and the moisture absorption rate was $0.10 \%$. Compared with the original biochar, the contact angle of the modified biochar increased by $136.95^{\circ}$ and the moisture absorption rate decreased by $0.12 \%$.

\subsection{FT-IR and TGA Analysis}

The surface functional groups of the original and modified biochar were detected using FT-IR spectroscopy [26]. As shown in Figure 6a, the spectra of the biochar before and after modification were basically consistent, indicating that the biochar was the same substance before and after modification, but the microstructure changed. Some proper functional groups on the surface of biochar were effectively identified such that the intensity of the wide adsorption band around $3400 \mathrm{~cm}^{-1}$ could be attributed to $\mathrm{O}-\mathrm{H}$ stretching of acid or to alcohol structures, that around 2368-2381 cm $\mathrm{cm}^{-1}$ could indicate the presence of carbon dioxide $(\mathrm{O}=\mathrm{C}=\mathrm{O})$, and around $1590-1850 \mathrm{~cm}^{-1}$ may indicate $\mathrm{C}=\mathrm{C}$ stretching from alkenes, around $1360 \mathrm{~cm}^{-1}$ may indicate the presence of $\mathrm{C}-\mathrm{O}, \mathrm{C}=\mathrm{O}$ and probably $\mathrm{C}-\mathrm{H}$ bending modes. The stretching vibration absorption peak around $1050 \mathrm{~cm}^{-1}$ of the modified hydrophobic biochar was significantly stronger and wider than that of the original biochar, indicating that the modified biochar was grafted with the modifier and generated a large amount of C-O-Si and Si-O [20,26-31]. Hydrophobic groups in KH-570 effectively bound to the surface of the biochar, forming a hydrophobic organic coating [20].

The thermal stabilities of the biochar before and after powder modification in an atmosphere of $\mathrm{N}_{2}$ were measured using TGA [9]. As shown in Figure 6b, the first weight loss occurred at $100{ }^{\circ} \mathrm{C}$, which was attributed to the removal of adsorbed water [32]. Before $200{ }^{\circ} \mathrm{C}$, the weight loss rate of original biochar was $5.21 \%$. However, the weight loss rate of the modified biochar was $2.11 \%$, which was significantly reduced, indicating that the surface hydrophobicity of the modified biochar was enhanced and the moisture absorption rate decreased. The second weight loss occurred at $400-600{ }^{\circ} \mathrm{C}$ due to the combustion of free carbon and ash in biochar. The decreasing trend of the modified biochar mass was smoother than that of the original biochar, indicating that the silane coupling agent coated on the surface of biochar delayed the combustion of carbon and ash. The results showed that the modified biochar exhibited better thermal stability than the original biochar. 

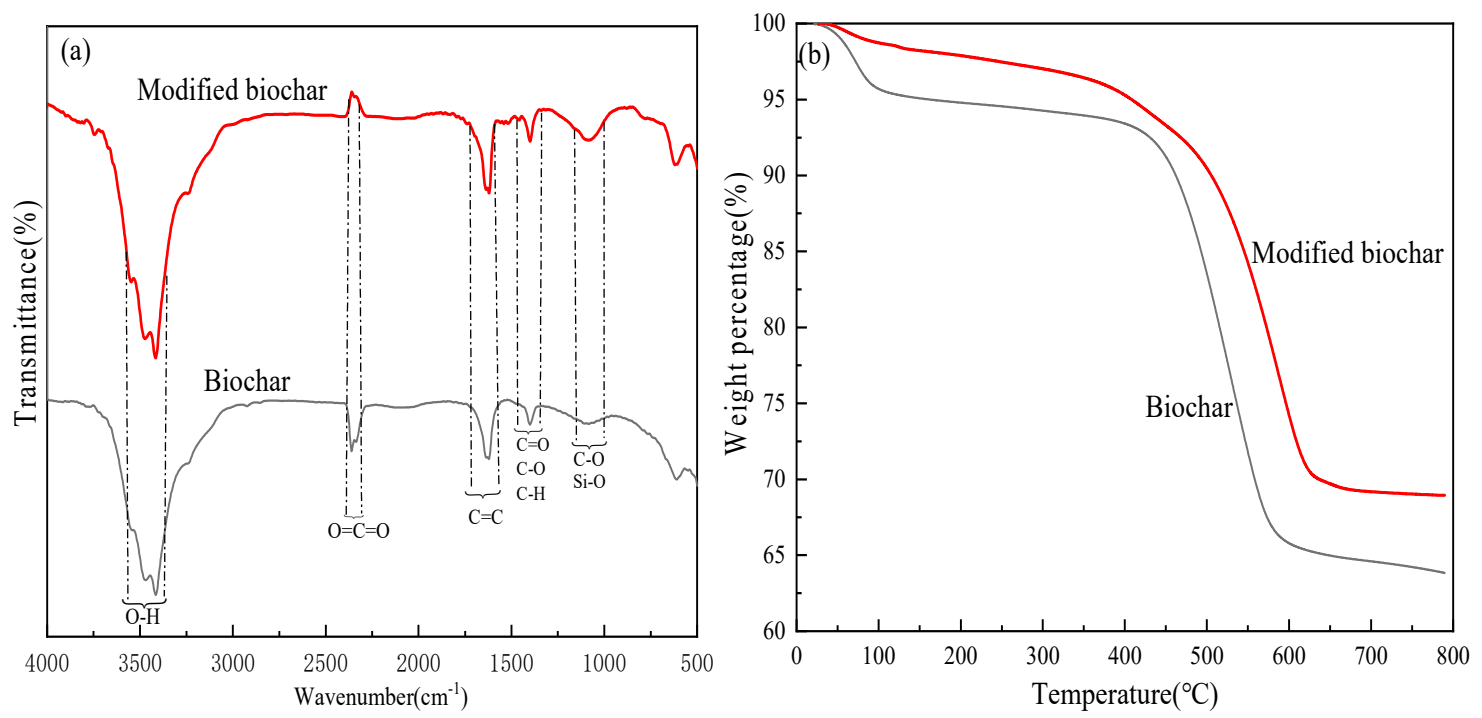

Figure 6. (a) Fourier transform infrared spectroscopy spectra and (b) thermogravimetric curves of biochar before and after modification.

\subsection{XRD Analysis}

The effects of silane coupling agent modification on the biochar were explored by characterizing them through XRD analysis. As shown in Figure 7, biochar before and after modification basically coincided, indicating that the surface hydrophobicity modification of the biochar by KH-570 had no significant effect on the phase composition of the biochar [21]. The XRD pattern of the biochar before and after modification was dominated by crystalline structures with a signal centered around $27^{\circ}$ corresponding to the (002) reflection as the most predominant [33]. High peak density was observed in the modified biochar, indicating that higher crystalline structures were formed [34]. The impurity characteristic peak of modified biochar decreased compared with that of original biochar, indicating that the modifier KH-570 had been coated on the surface of biochar.

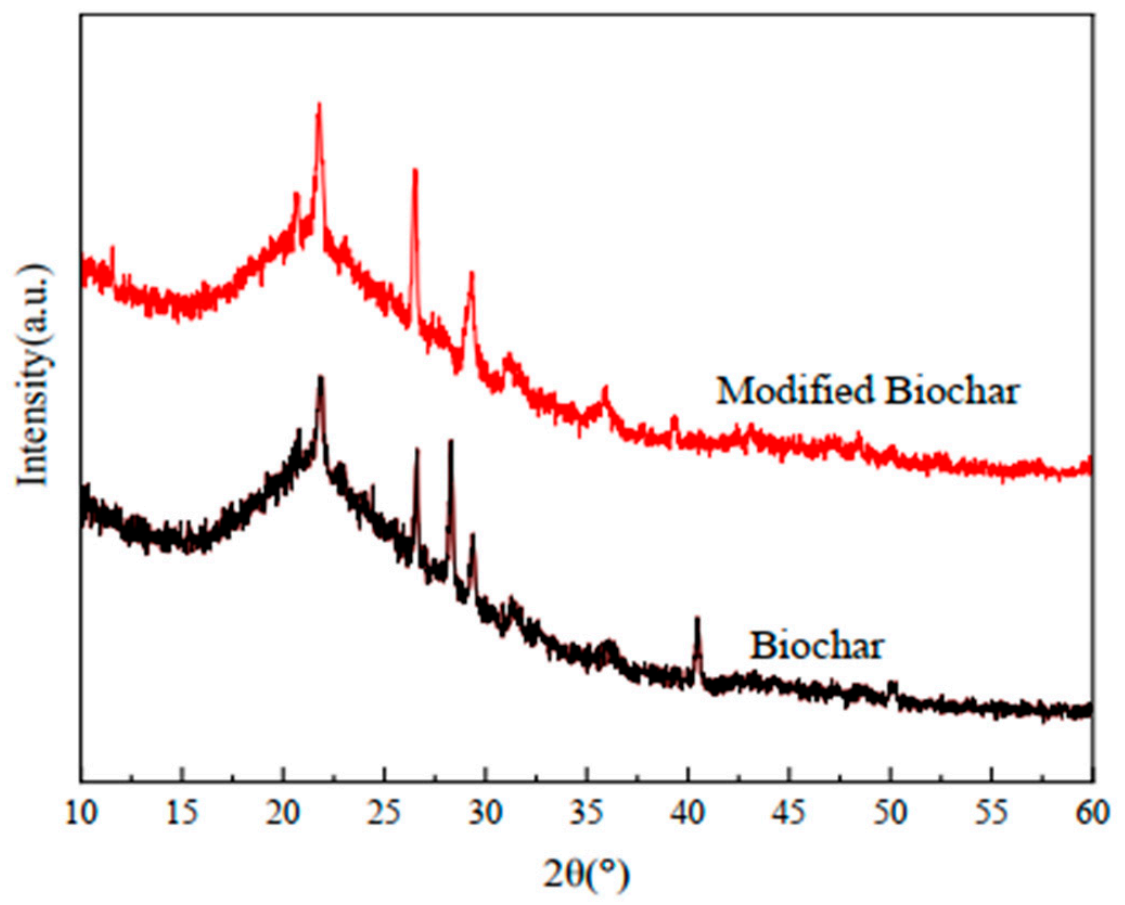

Figure 7. X-ray diffractometer images of biochar before and after modification. 


\subsection{SEM Analysis}

Figure 8 shows the surface morphology of biochar before and after modification. As shown in Figure 8a, rice biochar was tubular porous with a honeycomb-like structure and a rough surface [34]. Figure $8 \mathrm{~b}$ shows that the porous structure of the modified biochar does not change due to modification, and the surface of the modified biochar has an obvious covering layer [20], which was consistent with the previous characterization results.
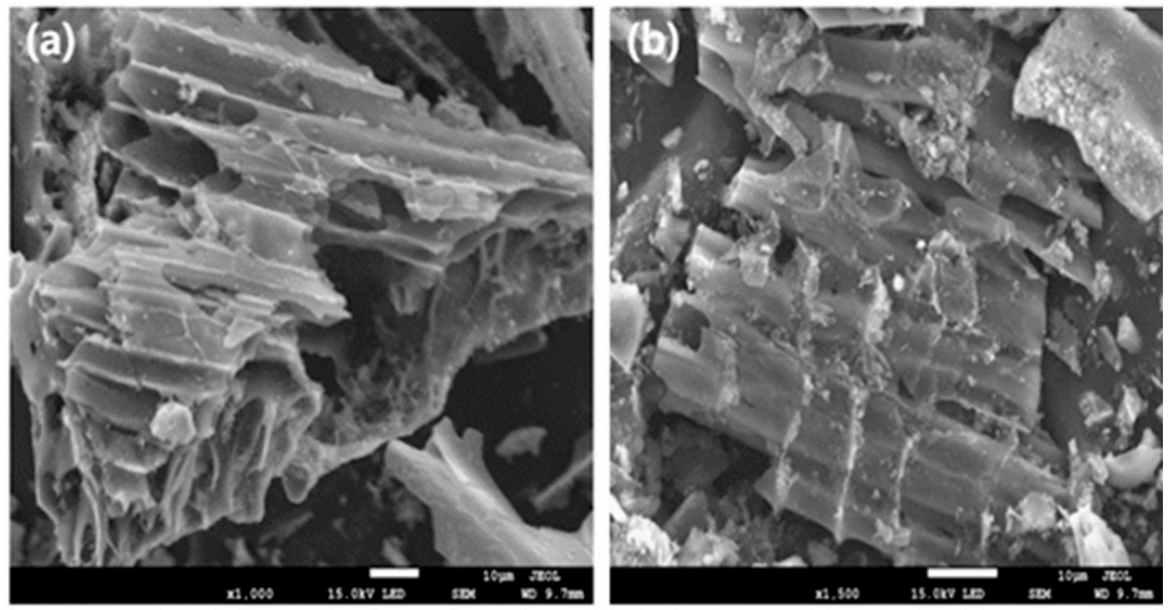

Figure 8. (a) Scanning electron microscope images of biochar and (b) modified biochar.

\subsection{Waterproof Performance}

The measured infiltration water of the biochar-amended soil was $200 \mathrm{~mL}$, and that in the hydrophobic biochar-amended soil was $20 \mathrm{~mL}$, which was significantly less than that in the biochar-amended soil. This result indicates that the waterproofing ability of the hydrophobic biochar-amended soil was significantly better than that of the biocharamended soil.

\section{Conclusions}

In this study, the biochar was modified by silane coupling agent KH-570 to improve its hydrophobicity. The optimum conditions for preparation of surface hydrophobic biochar were as follows: mass fraction of $\mathrm{KH}-570$ was $7 \%$, biochar dosage was $7 \mathrm{~g}$, and modification temperature was $60{ }^{\circ} \mathrm{C}$. The contact angle and hygroscopicity tests confirmed that the hydrophobicity of the surface-modified biochar was greatly increased compared with that of the original biochar. The contact angle of the modified biochar was $143.99^{\circ}$, which was $136.95^{\circ}$ higher than that of the original biochar. The moisture absorption rate was $0.10 \%$, which was $0.12 \%$ lower than that of the original biochar. The analysis results of TGA, XRD, and SEM before and after the biochar modification showed that the hydrophobic organic coating was formed on the surface of the modified biochar, resulting in the biochar turning from hydrophilic to hydrophobic surface. The simulated precipitation test indicated that the waterproof ability of the HBSC was significantly better than that of BSC.

Author Contributions: Conceptualization, software, formal analysis, writing-original draft, M.Z.; conceptualization, writing-review and editing, H.Z. (Hongxiang Zhu); supervision, writing-review and editing, B.X.; writing-review and editing, Y.T.; funding acquisition, project administration, supervision, writing-review and editing, X.S.; conceptualization, writing-review and editing, H.Z. (Hongxia Zhang); methodology, data curation, formal analysis, B.W. All authors have read and agreed to the published version of the manuscript.

Funding: This work was financially supported by National Natural Science Foundation of China (No. 51668014); Natural Science Foundation of Guangxi (No. 2018GXNSFGA281001); Science and Technology Major Project of Guangxi (GuikeAA18118013). 


\section{Institutional Review Board Statement: Not applicable.}

Informed Consent Statement: Not applicable.

Data Availability Statement: Not applicable.

Conflicts of Interest: The authors declare no conflict of interest.

\section{References}

1. Sadasivam, B.Y.; Reddy, K.R. Landfill methane oxidation in soil and bio-based cover systems: A review. Rev. Environ. Sci. Bio/Technol. 2014, 13, 79-107. [CrossRef]

2. Huang, D.; Xu, W.; Wang, Q.; Xu, Q. Impact of hydrogen sulfide on biochar in stimulating the methane oxidation capacity and microbial communities of landfill cover soil. Chemosphere 2022, 286, 131650. [CrossRef] [PubMed]

3. Parsaeifard, N.; Sattler, M.; Nasirian, B.; Chen, V.C.P. Enhancing anaerobic oxidation of methane in municipal solid waste landfill cover soil. Waste Manag. 2020, 106, 44-54. [CrossRef] [PubMed]

4. Bukh, P.G.; Charlotte, S.; Peter, K. Availability and properties of materials for the Fakse Landfill biocover. Waste Manag. 2011, 31, 884-894. [CrossRef]

5. Charlotte, S.; Alessio, P.; Bukh, P.G.; Peter, K. Evaluation of respiration in compost landfill biocovers intended for methane oxidation. Waste Manag. 2011, 31, 895-902. [CrossRef]

6. Huang, D.; Yang, L.; Xu, W.; Chen, Q.; Ko, J.H.; Xu, Q. Enhancement of the methane removal efficiency via aeration for biochar-amended landfill soil cover. Environ. Pollut. 2020, 263, 114413. [CrossRef]

7. Zhang, Y.; Zhang, H.; Jia, B.; Wang, W.; Zhu, W.; Huang, T.; Kong, X. Landfill $\mathrm{CH}_{4}$ oxidation by mineralized refuse: Effects of $\mathrm{NH}_{4}{ }^{+}-\mathrm{N}$ incubation, water content and temperature. Sci. Total Environ. 2012, 426, 406-413. [CrossRef]

8. He, J.; Feng, X.Y.; Zhou, L.R.; Zhang, L. The effect of leachate seepage on the mechanical properties and microstructure of solidified sludge when used as a landfill temporary cover material. Waste Manag. 2021, 130, 127-135. [CrossRef]

9. Liu, Y.; Gao, C.; Wang, Y.; He, L.; Lu, H.; Yang, S. Vermiculite modification increases carbon retention and stability of rice straw biochar at different carbonization temperatures. J. Clean. Prod. 2020, 254, 120111. [CrossRef]

10. Yargicoglu, E.N.; Reddy, K.R. Biochar-Amended Soil Cover for Microbial Methane Oxidation: Effect of Biochar Amendment Ratio and Cover Profile. J. Geotech. Geoenviron. Eng. 2017, 144, 1845. [CrossRef]

11. Gopinath, P.; Vo, D.; Gnana Prakash, D.; Adithya Joseph, A.; Viswanathan, S.; Arun, J. Environmental applications of carbon-based materials: A review. Environ. Chem. Lett. 2021, 19, 557-582. [CrossRef]

12. Srivatsav, P.; Bhargav, S.; Shanmugasundaram, V.; Arun, J.; Gopinath, P.; Bhatnagar, A. Biochar as an Eco-Friendly and Economical Adsorbent for the Removal of Colorants (Dyes) from Aqueous Environment: A Review. Water 2020, 12, 3561. [CrossRef]

13. Reddy, K.R.; Yargicoglu, E.N.; Yue, D.; Yaghoubi, P. Enhanced Microbial Methane Oxidation in Landfill Cover Soil Amended with Biochar. J. Geotech. Geoenviron. Eng. 2014, 140, 1148. [CrossRef]

14. Zhang, X.; Xia, J.; Pu, J.; Cai, C.; Tyson, G.W.; Yuan, Z.; Hu, S. Biochar-Mediated Anaerobic Oxidation of Methane. Environ. Sci. Technol. 2019, 53, 6660-6668. [CrossRef]

15. Wu, B.; Xi, B.; He, X.; Sun, X.; Li, Q.; Ouche, Q.; Zhang, H.; Xue, C. Methane Emission Reduction Enhanced by Hydrophobic Biochar-Modified Soil Cover. Processes 2020, 8, 162. [CrossRef]

16. Poupak, Y. Development of Biochar-amended Landfill Cover for Landfill Gas Mitigation, Chicago: University of Illinois at Chicago; United States of America: Chicago, IL, USA, 2011.

17. Scheutz, C.; Kjeldsen, P.; Bogner, J.E.; De Visscher, A.; Gebert, J.; Hilger, H.A.; Huber-Humer, M.; Spokas, K. Microbial methane oxidation processes and technologies for mitigation of landfill gas emissions. Waste Manag. Res. 2009, 27, 409-455. [CrossRef]

18. Majdinasab, A.; Yuan, Q. Performance of the biotic systems for reducing methane emissions from landfill sites: A review. Ecol. Eng. 2017, 104, 116-130. [CrossRef]

19. Sadasivam, B.Y.; Reddy, K.R. Adsorption and transport of methane in landfill cover soil amended with waste-wood biochars. J. Environ. Manag. 2015, 158, 11-23. [CrossRef]

20. Sun, X.; Qin, Y.; Wu, B.; Li, J.; Xue, C. Optimization of hydrophobic properties of biochar modified by silane coupling agent. Environ. Sci. Technol. 2019, 42, 68-73. (In Chinese)

21. Chen, K.; Li, P.; Li, X.; Liao, C.; Li, X.; Zuo, Y. Effect of silane coupling agent on compatibility interface and properties of wheat straw / polylactic acid composites. Int. J. Biol. Macromol. 2021, 182, 2108-2116. [CrossRef]

22. Fatemeh, A.; Navarchian, A.H. Recent advances in chemical surface modification of metal oxide nanoparticles with silane coupling agents: A review. Adv. Colloid Interface Sci. 2020, 286, 102298. [CrossRef]

23. Li, G.; Yue, J.; Guo, C.; Ji, Y. Influences of modified nanoparticles on hydrophobicity of concrete with organic film coating. Constr. Build. Mater. 2018, 169, 1-7. [CrossRef]

24. Jiang, H.; Ye, Y.; Lu, P.; Zhao, M.; Xu, G.; Chen, D.; Song, T. Effects of torrefaction conditions on the hygroscopicity of biochars. J. Energy Inst. 2021, 96, 260-268. [CrossRef]

25. He, L.H.; Li, L.; Zhou, C.; Li, W.H. Hydrophobic surface modification of diatomit with silane coupling agent KH-570. Mod. Chem. Ind. 2014, 34, 93-97. (In Chinese) 
26. Yang, Q.; Sun, Y.; Sun, W.; Qin, Z.; Liu, H.; Ma, Y.; Wang, X. Cellulose derived biochar: Preparation, characterization, and Benzo[a]pyrene adsorption capacity. Grain Oil Sci. Technol. 2021, 4, 182-190. [CrossRef]

27. Wang, L.; Zhang, S.; Wu, S.; Long, Y.; Li, L.; Zheng, Z.; Hei, Y.; Zhou, L.; Luo, L.; Jiang, F. Controlling wettability of AgI/BiVO 4 composite photocatalyst and its effect on photocatalytic performance. J. Alloys Compd. 2020, 835, 155367. [CrossRef]

28. Manfrin, J.; Gonçalves, A.C., Jr.; Schwantes, D.; Conradi, E., Jr.; Zimmermann, J.; Ziemer, G.L. Development of biochar and activated carbon from cigarettes wastes and their applications in $\mathrm{Pb}^{2+}$ adsorption. Environ. Chem. Eng. 2021, 9, 104980. [CrossRef]

29. Tran, H.N.; Tomul, F.; Thi Hoang Ha, N.; Nguyen, D.T.; Lima, E.C.; Le, G.T.; Chang, C.-T.; Masindi, V.; Woo, S.H. Innovative spherical biochar for pharmaceutical removal from water: Insight into adsorption mechanism. J. Hazard. Mater. 2020, $394,122255$. [CrossRef]

30. Stylianou, M.; Christou, A.; Dalias, P.; Polycarpou, P.; Michael, C.; Agapiou, A.; Papanastasiou, P.; Fatta-Kassinos, D. Physicochemical and structural characterization of biochar derived from the pyrolysis of biosolids, cattle manure and spent coffee grounds. J. Energy Inst. 2020, 93, 2063-2073. [CrossRef]

31. Khoshnood Motlagh, E.; Asasian-Kolur, N.; Sharifian, S.; Ebrahimian Pirbazari, A. Sustainable rice straw conversion into activated carbon and nano-silica using carbonization-extraction process. Biomass Bioenergy 2021, 144, 105917. [CrossRef]

32. Chen, R.; Zhao, X.; Jiao, J.; Li, Y.; Wei, M. Surface-Modified Biochar with Polydentate Binding Sites for the Removal of Cadmium. Int. J. Mol. Sci. 2019, 20, 1775. [CrossRef] [PubMed]

33. Clurman, A.M.; Rodríguez-Narvaez, O.M.; Jayarathne, A.; Silva, G.D.; Ranasinghe, M.I.; Goonetilleke, A.; Bandala, E.R. Influence of surface hydrophobicity/hydrophilicity of biochar on the removal of emerging contaminants. Chem. Eng. J. 2020, 402, 126277. [CrossRef]

34. Hong, N.; Cheng, Q.; Goonetilleke, A.; Bandala, E.R.; Liu, A. Assessing the effect of surface hydrophobicity/hydrophilicity on pollutant leaching potential of biochar in water treatment. J. Ind. Eng. Chem. 2020, 89, 222-232. [CrossRef] 